\title{
Morbidity Surveillance in the British Army - the first 12 months
}

\author{
Maj LA Wright \\ QARANC \\ Ministry of Defence, Army Medical Directorate 5, Keogh Barracks, Ash Vale, Aldershot, GU12 $5 R R$
}

Professor V Demicheli
MD, Msc
Department of Medical Statistics - University of Pavia

Professor WJ Gillespie

CHM, FRACS (Orth)

Department of Orthopaedic Surgery, Clinical Research Unit, Princess Margaret Rose Orthopaedic Hospital, Fairmilehead,

Edinburgh, EH10 7ED

\section{Lt Col TO Jefferson}

MRCGP, MFPHM, RAMC

Ministry of Defence, Army Medical Directorate 5, Keogh Barracks, Ash Vale, Aldershot, GU12 SRR

SUMMARY: This paper describes the data obtained during the first 12 months of the morbidity surveillance system used, world-wide, by the British Army in operational and non-operational settings and the economic impact of such morbidity in terms of estimated working days lost. Analysis is provided on primary health care and dental morbidity, the surveillance of patients undergoing physiotherapy and those Service personnel cared for by the NHS. Thesurveillance of the latter population shows a high burden of morbidity which, previously, has never been quantified The most frequent cause of attendance within primary health care is injuries (all causes) with an annual total of 77,254 - a rate per 1,000 personnel per month of 51.92. This leads to an annual loss of manpower, in terms of estimated 8 working days lost of 127,839 - a rate per 1,000 personnel per month of 85.91. Army Training Regiments (ATRs - 5 sites), Infantry Training Centres (ITCs-2 sites) and the Royal Military Academy Sandhurst (RMAS) are grouped together as 8 Selected Training Establishments (STEs) and show attendance rates higher than the mean for all causes. Summarje results of Cochrane systematic reviews presenting up-to-date concise information on experimental evidence as to which preventive interventions should be used to diminish the notable impact of injuries on Army personnel are also given.

\section{Introduction}

Not all health problems have the same importance for the Armed Forces as some problems may have a different impact than others. As resources are finite it is incumbent on Service health care workers to identify those problems which represent the worthiest targets for intervention, and prioritise them accordingly. The key to achieving rational and effective prioritisation is information on the weight of health problems facing the Armed Forces and the success in tackling them. Over the years, in the Army, a variety of $a d$-hoc data collection systems have been used that were collected incompletely, rarely interpreted and provided little feed-back to originators. Crucially, such systems were never used to inform the decision-making process.

Following extensive trials in 1992 and 1994, the Army Medical Directorate (AMD) devised the J95 morbidity surveillance system and carried out a pilot study from March to July 1995 (1). J95 is designed to be used in operational and non-operational settings and to be flexible enough to allow for variation of event categories dictated either by a different morbidity pattern or by different operational requirements. $\mathrm{J} 95$ forms a basis of a systematic needs assessment programme which may be the vehicle for targeting health care resources according to most need.

J95 groups the reasons for attendance at Army Medical Services (AMS) outlets into categories, using the World Health Organisation's International Classification of Diseases (ICD), and provides estimates of the number of working days lost thus showing the impact of disease on the Army's capability to carry out its mission. It is based on the collection (in a mainly manual fashion), collation and feed-back of data from Army unit medical centres (primary care) world-wide.

The morbidity burden represented by those personnel who are sick in the care of the NHS is obtained by the Military Administrative Officers (Civil Hospitals) (MAO $(\mathrm{CH})$ ), who are located within the Medical Branches of Divisional/District headquarters in the UK. Other variants of the J95 system (J95D and J95P) focus on particular sub-categories of morbidity seen by dental officers and physiotherapists, demonstrating the flexibility of the system.

This paper describes the morbidity data collected during the first 12 months of the J95 system including variants and differing locations. It also includes a summary of the results of a Cochrane systematic review, carried out by members of the Cochrane Musculo-Skeletal Group at the

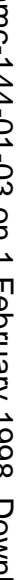


University of Edinburgh on behalf of AMD (2), which presents up-to-date summary information on experimental evidence as to which preventive interventions should be used to diminish the notable impact of injuries on Army personnel. Cochrane reviews provide the best source of effectiveness estimates. Interventions which have not been evaluated or have been found to be ineffective are penalised in terms of the estimated number of working days lost they can prevent or save. Thus, only effective interventions should be invested in, as they are the only ones shown to be likely to diminish the impact of morbidity on force levels.

\section{Methods}

Each Army medical centre submits a monthly morbidity return to the J95 cell at AMD5 showing the number of attendances (first and subsequent) made under the current 22 J95 Event codes as follows:

1. Intestinal Infectious Disease.

2. Sexually Transmitted Diseases (STDs).

3. Other Infectious Diseases.

4. Alcohol and Drug Abuse and Dependencies.

5. Mental Disorders.

6. Eye Disorders.

7. Asthma.

8. Disease of the Respiratory system other than Asthma.

9. Diseases of the Oral Cavity, Salivary Glands and Jaws.

10. Peptic Ulcers.

11. Other Diseases of the Digestive System.

12. Gynaecological problems, Pregnancy and complications of pregnancy.

13. Dermatological problems.

14. Internal Derangement of Knee and Joint.

15. Dorsopathies.

16. Other Musculo-Skeletal Diseases.

17. Injuries - when due to RTAs.

18. Injuries - when due to all other causes other than War and RTAs.

19. Injuries - when due to Operations and War.

20. Effect of reduced Temperature, Heat and Light.

21. Complications of Medical Care.

22. Other Diseases and symptoms not classified elsewhere.

In addition, information is obtained on what happens to the individual (disposal) as a result of such attendance i.e. excused all duties or placed on light duties, and/or if they have been referred to hospital - for admission or specialist consultation. Analysis is carried out by AMD using EPI Info shareware, produced by CDC Atlanta and the World Health Organisation.

To carry out surveillance of the population covered by $\mathrm{MAO}(\mathrm{CH})$ s two formats are used, the first to capture information on Army personnel admitted to civilian hospitals and the other to gather information on those individuals who are sick at home (primary care). This surveillance commenced on 1 July 1996 and 100\% compliance was achieved for the period July - December 1996.

J95D is the dental morbidity surveillance system launched in conjunction with J95 on 1 January 1996 an breaks down the original event code 9 (Diseases of the Oral Cavity, Salivary Glands and Jaw) into 9 sub-division to allow an in-depth examination of the principal dentas causes of morbidity.

J95P is designed to survey the conditions treated b physiotherapists in primary health care and, like the dentaf surveillance system, sub-divides the J95 event codes t\$. allow an in-depth examination of the principal types of morbidity (soft tissue and musculo-skeletal injuriest assessed and treated by physiotherapists in military. primary care. In addition, J95P differentiates betweeß those injuries, or conditions, caused by acute trauma an $\mathbb{R}$. those due to overuse. The system was trialled in 4 ATRश during 1996 and a phased introduction into primary healt care physiotherapy commenced in May 1997.

\section{Results}

Primary Care

Despite a variable population, the system within the first six months of its existence achieved over $90 \%$ compliance as shown in Figure 1. This is a high rate when compaged to similar surveillance programmes. The most frequ伭

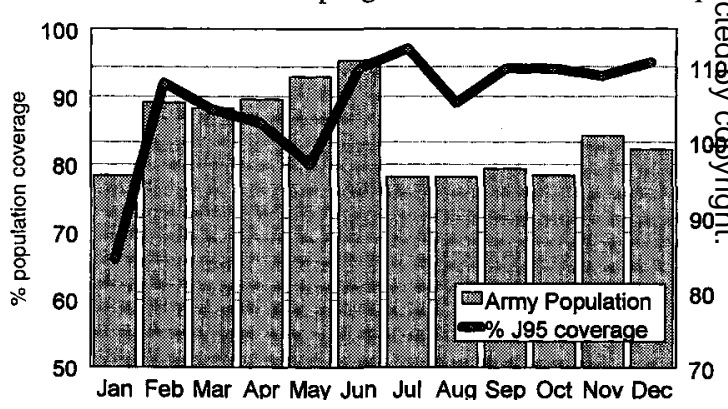

Fig 1. Total Army population and percentage of population covered per month by $\mathbf{J 9 5}$ Morbidity Surveillance System 1996.

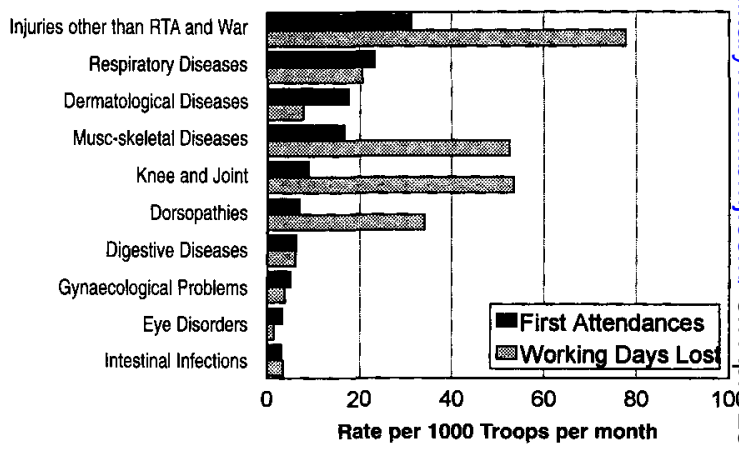

Fig 2. J95 Morbidity Surveillance System. Top ten causes of consultation. Rate of first attendances and estimated working days lost (per 1000 troops per month) 1996. 
Injuries other than RTA and WAR

- Division/Command/STE

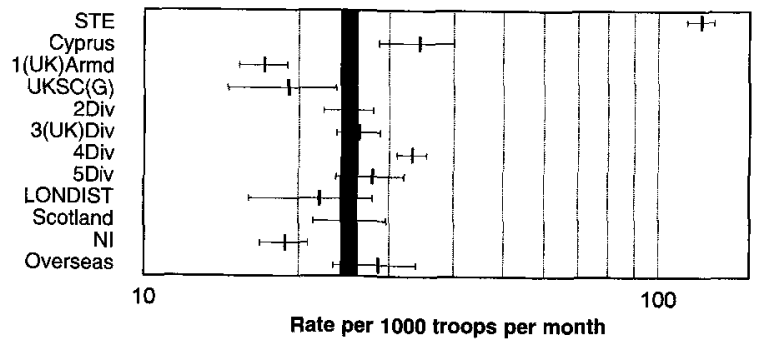

Respiratory diseases

Division/Command/STE

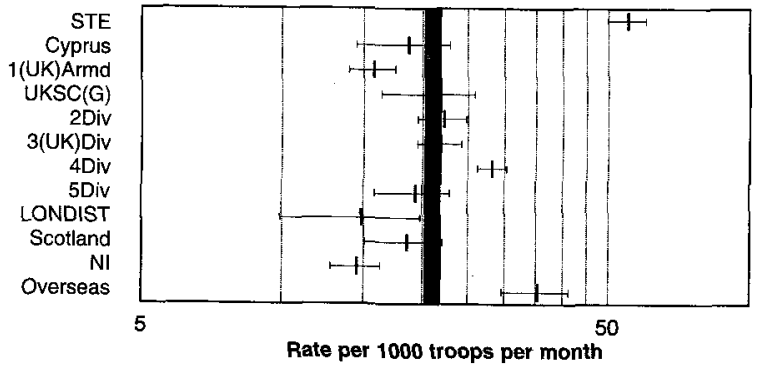

Overuse diseases of musculo-skeletal system.

Division/CommandSTE

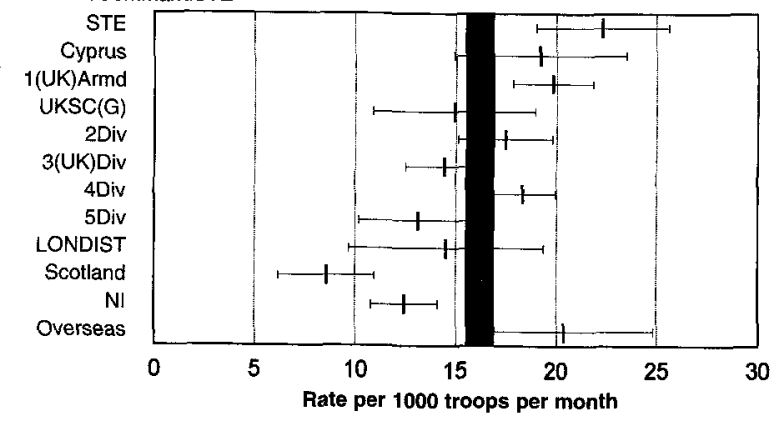

Internal derangement of the knee

Division/Command/STE

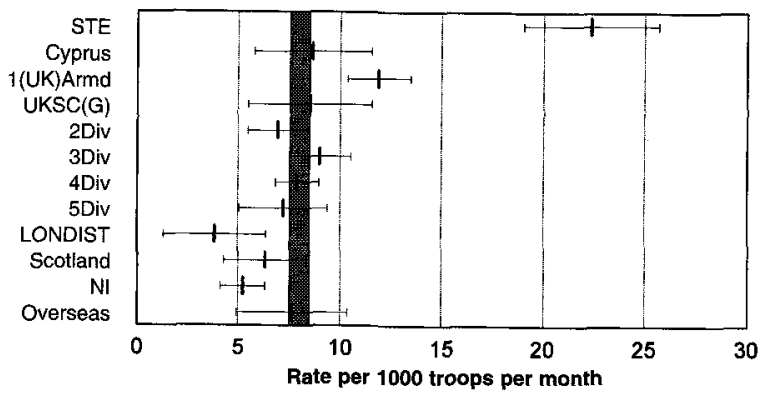

Fig 3. J95 Morbidity Surveillance System. Rate of first attendances for selected causes in each Division/

Command/STE (with $95 \%$ confidence interval of the rate) and comparison with the whole Army Rate (in shaded area).

NB. STE = Selected Training Establishments Overseas = Belize, Brunei, Canada, Hong-Kong, Kenya and Nepal. cause of attendance is injuries (all causes) with an annual total of 77,254 - a rate per 1,000 personnel per month of 51.92. This leads to an annual loss of manpower, in terms of estimated working days lost of 127,839 - a rate per 1,000 personnel per month of 85.91. Figure 2 reports the top ten causes of attendance during 1996, and their impact in terms of estimated working days lost, as rates per 1,000 troops per month. Injuries, and their long term consequences on joints, bones and muscles, take the lionshare of productivity losses. Other relatively frequent problems such as respiratory problems and dermatological conditions appear self-limiting in nature.

Figure 3 is a synopsis of four of the highest causes of attendance broken down by Division or Command and their relationship with the whole Army rate. Ninety five percent confidence intervals (shown by the horizontal bars) which do not cross the shaded area are significantly different from the Army mean. ATRs (5 sites), ITCs (2 sites) and the RMAS are grouped together as STEs and show attendance rates higher than the mean for all causes. This may be due to the high pressure competitive environment of STEs.

MAO(CH) Surveillance

Figure 4 shows the five main causes of attendance with civilian GPs i.e. out with the military system, for the period $\overparen{\mathbb{\Phi}}$ July - December 1996. Figure 5 shows the main causes of estimated working days lost within primary care for the same period.

The information collected from Secondary care relates 8 to the number of admissions (first and subsequent) to NHS hospitals and Figure 6 shows the five main causes ofo admission. Additional information was collected on the? number of days spent as an in-patient as well as any days granted as hospital sick-leave. The four main causes of production losses are shown in Figure 7.

The surveillance of this population shows a high burden of morbidity which, previously, has never been quantified. Injuries and mental disorders are the highest reported conditions which suggests chronicity. Given the geographic dispersion (i.e. UK-wide), the overburdened

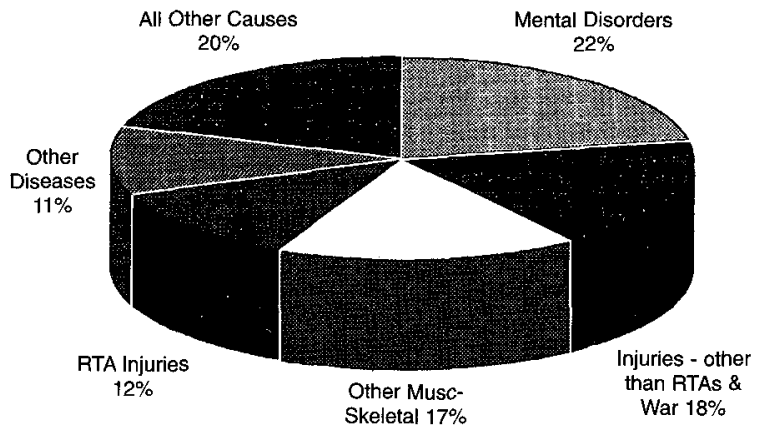

Fig 4. J95 MAO(CH) Morbidity Surveillance System. Five main causes of attendance with civilian GPs (July - December 1996). 


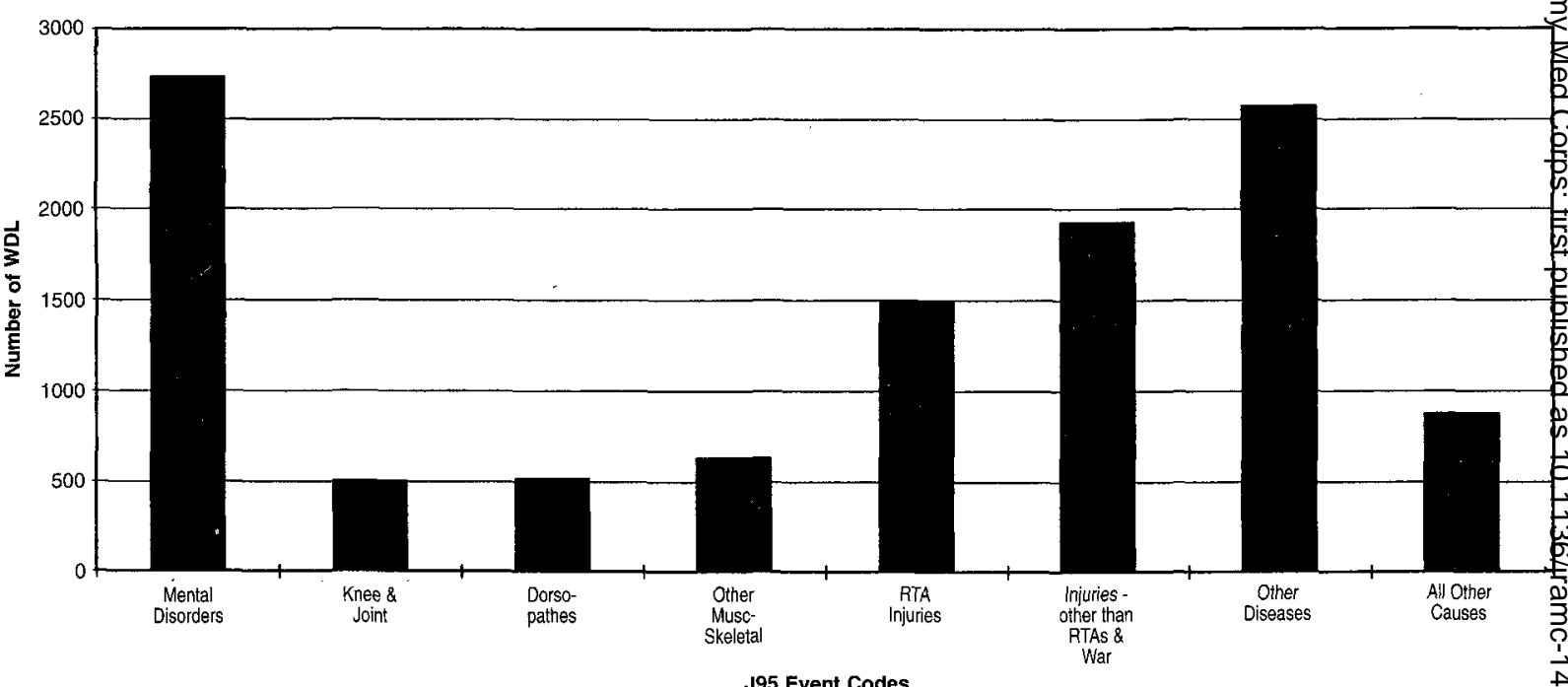

J95 Event Codes

Fig 5. J95 MAO(CH) Morbidity Surveillance System. Top seven causes of estimated working days lost within primary care (July - December 1996).

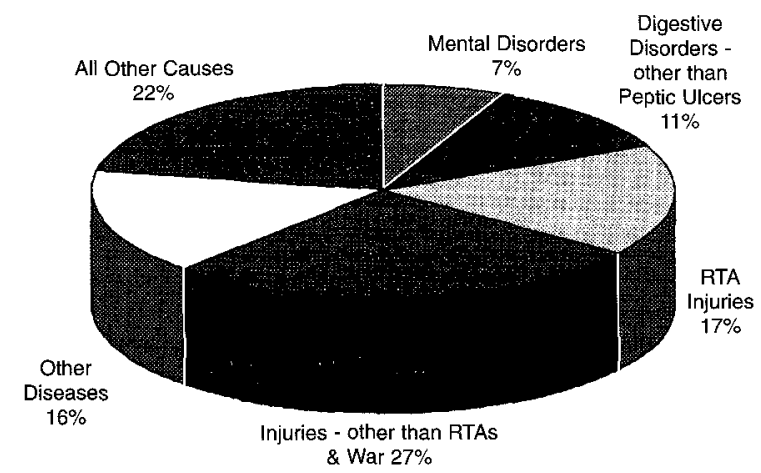

Fig 6. J95 MAO(CH) Morbidity Surveillance System. Five main causes of admission (first and subsequent) to NHS hospitals (July - December 1996).

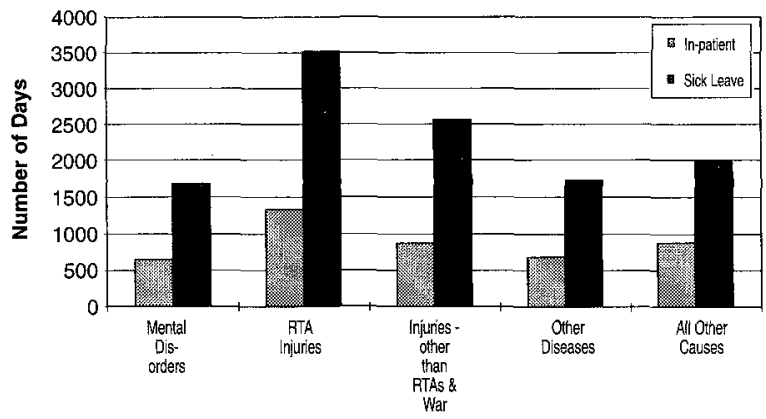

Fig 7. J95 MAO(CH) Morbidity Surveillance System.

Four main causes of production losses due to length of stay in hospital (in-patient) and hospital sick leave (July - December 1996).

MAO(CH)s and the closure of Defence Medical Services health care outlets, these are likely to be underestimates.

\section{Operational Surveillance}

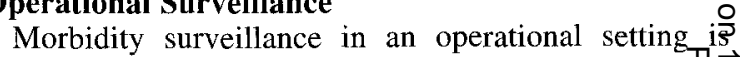
carried out for the Multi-National Division (South West (MND(SW)), which has included troops from Britant? Canada, the Netherlands, Malaya and the Cze्ge Republic, during their deployment in the former Repulgi of Yugoslavia (FRY). The data relates to the period to December 1996.

The top ten causes of attendance and estimaece working days lost, in rates per 100 troops per dayôें i尺 shown in Figure 8. Injuries still occur with the higless frequency, but respiratory and dermatological evento have a higher frequency than in non-operational settings Overall estimated working days lost are fewer, probabl迎 a reflection of operational circumstances but respirator $\vec{B}$ diseases have a comparatively higher productivit impact.

Medical planning parameters used by NATO (groupin morbidity under three headings of Disease, Non-Battle

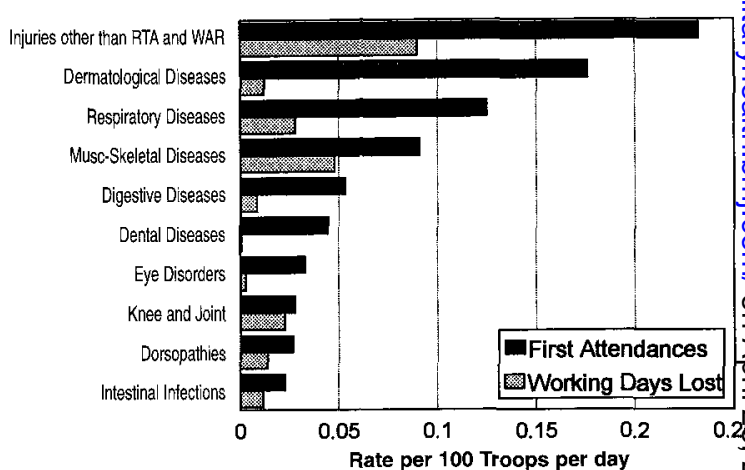

Fig 8. MND(SW). Top ten causes of consultation. Rate of first attendances and estimated working days lost (per 100 troops per day) May to December 1996 


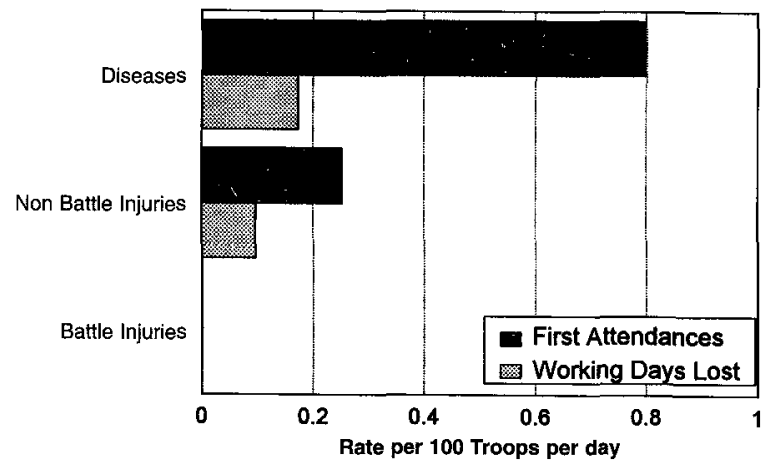

Fig 9. MND(SW). Disease, Non Battle Injuries and

Battle Injuries. Rate of first attendances and estimated working days lost (per 100 troops per day) May to December 1996.

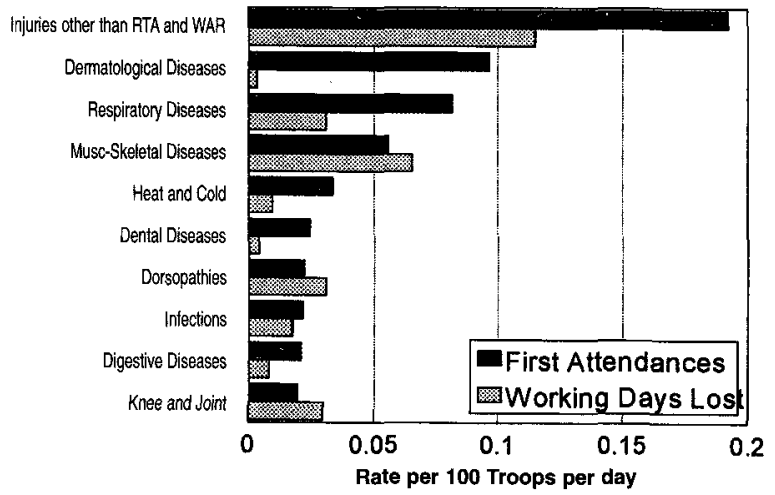

Fig 10. Exercise Purple Star. Top ten causes of consultation. Rate of first attendances and estimated working days lost (per 100 troops per day) 1996.

Injury and Battle Injury) is based on the assumption that, daily, $1.35 \%$ of deployed troops will seek medical assistance due to disease and $0.05 \%$ due to non-battle injury. Figure 9 shows that, within $\mathrm{MND}(\mathrm{SW})$, the daily rate for disease was $0.8 \%$ and for non-battle injuries $0.25 \%$, a serious underestimation of non-battle injuries by a factor of five. The nature of current operations in the FRY is reflected by the almost complete absence of Battle Injuries ( $0 \%$ for working days lost and $0.001 \%$ for attendance against a planning expectation of $3.6 \%)$.

\section{Exercise Surveillance}

Morbidity surveillance was carried out on a tri-Service exercise - Exercise Purple Star - in the United States of America in the early summer of 1996 . The top ten causes of attendance and estimated working days lost is shown in Figure 10. The morbidity profile is similar to that shown in Figure 8 i.e. an operational setting, with a small but significant increase for climatic injuries (mainly due to heat).
Table 1. J95D Morbidity Surveillance System. Total number of attendances and rate per 1000 personnel per month for each Event 1996

\begin{tabular}{|l|l|l|}
\hline $\begin{array}{l}\text { Event } \\
\text { (Sub-Division J95 Code 9) }\end{array}$ & $\begin{array}{l}\text { Total } \\
\text { Attendances }\end{array}$ & $\begin{array}{l}\text { Rate per } \\
\mathbf{1 , 0 0 0}\end{array}$ \\
\hline 9.1 Trauma & 2,154 & 2.28 \\
\hline 9.2 Failed Restoration & 11,071 & 11.74 \\
\hline 9.3 Caries (Dental Decay) & 1,915 & 2.01 \\
\hline 9.4 Infection - Soft Tissue & 3,426 & 3.63 \\
\hline 9.5 Infection - Hard Tissue & 4,345 & 4.60 \\
\hline 9.6 Impacted Teeth (wisdom teeth) & 2,538 & 2.69 \\
\hline 9.7 Damaged/Lost Denture & 371 & 0.39 \\
\hline 9.8 Sensitivity & 1,385 & 1.46 \\
\hline 9.9 Other & 2,437 & 2.58 \\
\hline Total & 29,642 & 31.38 \\
\hline
\end{tabular}

\section{Dental Morbidity}

Table 1 shows a total number of attendances and the rate, per 1,000 troops per month, for the dental event codes. The total number of estimated working days lost due to dental morbidity is very small if compared to other causes (343). Two factors need to be considered when analysing this data: firstly a very high proportion of dental surgery activity is of a preventive nature and secondly, the vast majority of personnel receive immediate treatment which alleviates symptoms and in many cases prevents the need for additional care.

The number of attendances (over one quarter of the total Army strength) which contrast with the relatively few estimated working days lost, illustrate that work carried out by the Army Dental Services (ADS) prevents a significant amount of personnel becoming casualties of a potentially more serious and debilitating nature. Routine inspection and treatment programmes, provided by the ADS, are not included in morbidity attendance, but such attendances obviously influence data by diagnosing and treating nonsymptomatic disease. Any reduction in ADS capability to deliver preventive care would result in an increase in working days lost.

Operational dental surveillance has been carried out in MND(SW) since January 1996. The results show total attendances of 3,468 with an operational rate per 1,000 troops nearly double that in non-operational settings. Such an increase is to be expected in an operational environment. Separate returns were collected for Regular and TA/Reservist personnel which show a morbidity rate of 27 per 1,000 personnel per month and 43 per 1,000 personnel per month respectively, confirming the view that the volunteer's basic dental standard is lower than that of regular soldiers.

\section{Physiotherapy Surveillance}

Figure 11 shows the five most prevalent J95P events at ATRs, in rates per 1,000 personnel per month. The predominance of lower limb problems reflects the nature of military training. There is also a very high proportion of subsequent attendances for the same problems. 


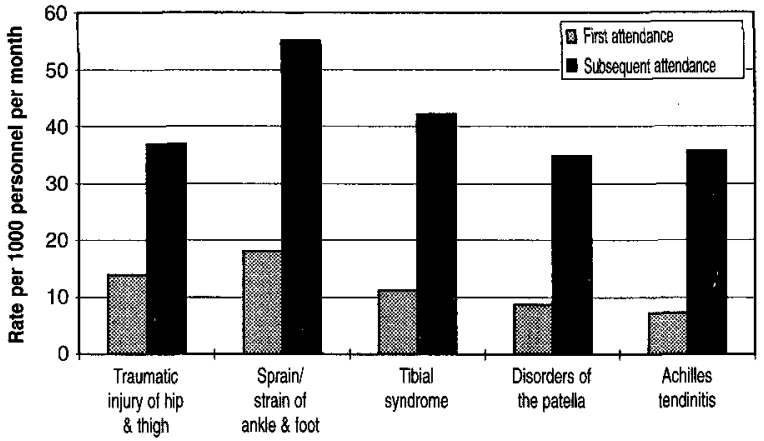

Fig 11. J95P Morbidity Surveillance System. Five main causes of attendance of physiotherapy at ATRs.

\section{Interventions}

Table 2 presents a list of interventions, each with an annual effectiveness estimate, expressed in terms of working days lost, should the intervention be adopted Army-wide. Estimates of effectiveness are based on Cochrane reviews of international experimental evidence (mainly randomised controlled trials) that were carried out on behalf of AMD by members of the Cochrane Musculo-Skeletal Group at the University of Edinburgh.

Additional risk factors for injury, which have been identified experimentally, include smoking more than 10 cigarettes per day and being aged over 24 years. The original trials, which provided the evidence, were carried out in military populations.

For those interventions which are not listed no reliable experimental evidence exists, or if it does, it is hidden where reviewers could not locate it. The Cochrane Musculo-Skeletal Group has also produced a similar list of treatment interventions which should be circulated to AMS units in the future.

\section{Discussion}

The operational use of J95 in the FRY during 1996 ha\$ led to its adoption by the North Atlantic Treat $y^{\circ}$ Organisation (NATO) for morbidity surveillance by alo nations participating in the current deployment. Thi allows comparison of data by deployment, nationality and geographical location. In addition, the body os evidence obtained can be used as a medical resourcing tool for any similar future deployments i.e. Operation Other than War (OOTW).

Evidence from the J95 morbidity surveillance systen shows that the biggest threat to our Army is represented by injuries and conditions due to the overuse of muscles. and skeleton. In order to combat the rising tide of injuries, commanders at all levels on whose shoulders the्छ responsibility of injury-avoidance lies, require information both on the nature and impact of injuries, and on the way to prevent them.

Following the evaluation of data from the first 18 months of the J95 system and the feed-back/constructive comments provided by the users of $\mathrm{J} 95$, a review of the system is to be undertaken in June 1997 with any change implemented from 1 January 1998. The review wilf involve assessment of the J95 event codes and theip suitability for continued usage based on the evidence the first years data. Some of the present codes now require expansion, for example, the event code for othes injuries (code 18). Additional codes may also of required, for example, some of those conditions. previously covered by other diseases (code 22).

Although a predominantly paper-based systemoit present, it is intended that J95 (and its successors) evolve, in the future, into an electronic system lin with the health care information systems (operational an non-operational) currently being developed by the Britis Armed Forces, thereby dispensing with the need for paper format.

Table 2. Cochrane Review. Recommended preventive interventions on selected injuries by estimated yearly number of lost working days prevented.

\begin{tabular}{|c|c|c|c|}
\hline Risk factor & Injury & Intervention & $\begin{array}{c}\text { Estimated } \\
\text { Working } \\
\text { Days Lost/ } \\
\text { Year Prevente }\end{array}$ \\
\hline Sports Training & Ankle Sprain & Ankle Brace & 2,926 \\
\hline Previous Injury & Ankle Sprain & Avoidance & 1,463 \\
\hline Sports Training & Knee Injury & Knee Brace & 2,290 \\
\hline General Physical Activity & Stress Fractures of Lower Limbs & Shock-Absorbing Insoles & 294 \\
\hline General Physical Activity & Stress Fractures of Lower Limbs & Leg Brace Following stress Fracture & 1,480 \\
\hline Running & Stress Fractures of Lower Limbs & Running Less Than $120 \mathrm{Kms}$ over a 10 Week Period & $891^{*}$ \\
\hline General Physical Activity & Overuse Lower Limb Injury & Reduce Intensity of Running and Marching & 42,007 \\
\hline Recruit Training & Stress Fractures of Lower Limbs & Delay Introduction of Boots & 216 \\
\hline General Physical Activity & Stress Fractures of Lower Limbs & $\begin{array}{l}\text { Running No More Than } 3 \text { Times/Week for } 30 \text { Minutes } \\
\text { Per Session }\end{array}$ & $891^{*}$ \\
\hline
\end{tabular}




\section{REFERENCES}

1. JefFerson TO, Demicheli V, Macmillan AHM. Pilot study of the introduction of the $\mathrm{J} 95$ health data collection system. J R Army Med Corps 1996; 142:25-29.
2. JefFerson TO. The Army and the Cochrane Collaboration (editorial). J R Army Med Corps 1995; 141:57-58. 